\title{
Effects of Housing Systems on Physiological and Immunological Parameters in Laying Hens
}

\author{
Sung-Young Kang, Young-Hyun Ko, Yang-Soo Moon, Sea-Hwan Sohn and In-Surk Jang* \\ Department of Animal Science \& Biotechnology, Gyeongnam National University of Science and Technology, \\ Chilam-Dong 150, Jinju, Gyeongnam, 660-758, South Korea
}

\begin{abstract}
The aim of this study was to assess the effects of housing systems on physiological and immunological responses as stress indicators in laying hens. A total of 500 White Leghorn aged 16 weeks were allotted into ten conventional cages (10 birds/cage and $\left.810 \mathrm{~cm}^{2} / \mathrm{bird}\right)$ and four floor pens (100 birds/pen and $\left.2,800 \mathrm{~cm}^{2} / \mathrm{bird}\right)$ for 24 weeks. The hens housed in conventional cages with higher stocking density resulted in a significantly $(\mathrm{P}<0.05)$ lower BW compared with those housed in floor pens with lower stocking density without affecting the relative weights of immune organs between housing conditions. In plasma biochemical values, cholesterol and corticosterone were significantly $(\mathrm{P}<0.05)$ lower in the hens housed in floor pens compared with those housed in conventional cages. In pro-inflammatory cytokines, hepatic interleukin (IL)-10 and interferon-gamma (IFN- $\gamma$ ) levels were significantly $(\mathrm{P}<0.05)$ higher in the hens housed in conventional cages compared with those kept in floor pens. Splenic and thymic IFN- $\gamma$ expression was significantly $(\mathrm{P}<0.05)$ up-regulated in the hens kept in conventional cages compared with those kept in floor pens without affecting IL-1, IL-10, lipopolysaccharide- induced tumor necrosis factor- $\alpha$ factor (LITAF) and inducible nitric oxide synthase (iNOS). In the bursa of Fabricius, IL-10 and iNOS expression of the hens housed in conventional cages were significantly $(\mathrm{P}<0.05)$ higher compared with those of the hens housed in floor pens. In conclusion, layers housed in conventional cages enhanced plasma cholesterol, corticosterone and some pro-inflammatory cytokines in the immune organs compared with those in floor pens.
\end{abstract}

(Key words : Conventional cages, Floor pens, Corticosterone, Inflammatory cytokines, Laying hens)

\section{INTRODUCTION}

To maximize productivity of laying hens, it is nowadays common practice to provide the most integrated and intensified housing conditions such as multiple-cages with high stocking density. At present, the housing of laying hens in conventional cages with higher stocking density is the predominantly applied system in many countries worldwide, although this system has been criticized for undesirable effects of social activities, behaviour, health and even the hen's welfare viewpoint (Nicol, 1987; Baxter, 1994; Freire et al., 2003; Albentosa and Cooper, 2004). Today, much concern is focused on housing conditions as it relates to the serious welfare concern of laying hens (Baxter, 1994). As a consequence of growing concerns, conventional cages were banned in the European Union from 2012. Therefore, it is crucial to determine the relationship between housing conditions and physiology as precisely as possible from the hen's stress and welfare viewpoint. Thus, a number of studies have been conducted to assess the effects of housing conditions on productivity, physiology, stress and welfare in hens (Rodenburg et al., 2005; Platz et al., 2009; Sherwin et al., 2010).

There was an evidence that social stressors induced by housing systems and stocking density affected production efficiency, physiological responses, susceptibility to harmful pathogens and mortality (Awadalla, 1998; Platz et al., 2009), leading to the threat of bird health and welfare in birds. In fact, the housing of conventional cages restricts naturally occurring social and behavioral activities such as free moving, perching, nesting and dustbathing, which has been ultimately associated with increasing stress responses as indicated by blood parameters and corticosterone level in hens (Mashaly et al., 1984; Shini, 2003). However, the appropriate way to assess physiological responses to monitor stress and welfare of hens under various husbandry

* Corresponding author: In-Surk Jang, Department of Animal Science \& Biotechnology, Gyeongnam National University of Science and Technology, Chilam-Dong 150, Jinju, Gyeongnam, 660-758, South Korea. Tel : 82-55-751-3236, Fax: 82-55751-3267, E-mail address: isjang@gntech.ac.kr 
conditions are extremely difficult (Puvadolpirod and Thaxton, 2000) because birds are exposed to a variety of external and internal stressors. Currently, conflicting studies reported that housing conditions affected (Siegal, 1985; Shini, 2003) or unaffected (Gibson et al., 1986; Singh et al., 2009) stress parameters including hematological values, corticoterone level and antibody production in birds. There is still a lack of reliability regarding the effects of housing conditions on physiological indicators because of a much more complexity of the design of the studies including the type and stocking density of housing facilities, the extent of environmental conditions, the diversities of genetics, and the sort of physiological indicators (Cook, 1991; Cheng and Muir, 2004; Buijs et al., 2009).

As a result of stress assessment, it is thus necessary to investigate specific physiological parameters that can be applied to assess the level of stress and welfare in hens. In particular, it is evident that cytokines play a crucial role in the interplay between the immune and endocrine system during acute and chronic stressors (Felten et al., 1998; Shini et al., 2010a). Currently, it has been reported that coricosterone level induced by stressors is involved in immune function through their effects on pro-inflammatory cytokines (Shini and Kaiser, 2009). Previous studies with laying hens also demonstrated that environmental stressors such as cold or heat stress and stocking density affected inflammatory cytokine expression in immune system (Mashaly et al., 2004; Hangalapura et al., 2006; Kang et al., 2011). We hypothesized that the chronic social stressors attributed to undesirable housing systems with higher stocking density could modulate immunity through corticosterone production to meet the needs of hens to maintain homeostasis.

Thus, we applied two different housing facilities and stocking densities, which could differentiate the status of stress and well-being of hens, to evaluate the combined effects of two social stressors on blood biochemical parameters and multiple pro-inflammatory cytokine expressions as stress indicators in laying hens.

\section{MATERIALS AND METHODS}

\section{Chickens and experimental design}

White Leghorn chicks produced at the experimental farm of Gyeongnam National University of Science and Technology,
Korea, were reared under pullet battery cages in a room equipped with temperature and on a light/dark cycle set. At 16 weeks of age, all birds were weighed and randomly allocated to two different housing systems (conventional cages vs. floor pens) as described below for 24 weeks. Hens and cockerel were mixed at a ratio of $9: 1$. All hens were banded in the legs, prior to their release into each housing system. All birds were daily given the same standard commercial diet containing $18 \%$ crude protein, $10,878 \mathrm{~kJ}$ of $\mathrm{ME} / \mathrm{kg}, 4.0 \%$ crude fat, $4.0 \% \mathrm{Ca}$ and $0.84 \% \mathrm{P}$ ad libitum in both housing conditions throughout the entire experiment period ( 24 weeks). The animal handling procedures of the present study were approved by the institutional animal care and use committee (IACUC) of the university.

\section{Housing conditions}

Two housing systems including conventional cages and floor pens were placed in adjacent rooms within the same facilities. In conventional cages, a total of 100 birds were randomly housed to 10 conventional cages with a gender ratio of 9 female to 1 male per cage $\left(810 \mathrm{~cm}^{2} /\right.$ bird $)$. The size of conventional cages was $90 \mathrm{~cm}$ in width by $90 \mathrm{~cm}$ in length by $66 \mathrm{~cm}$ in height with the wire floor slightly tilted from the rear to the front. The cages with a feeder in front and water cup at the back were arranged in 2 tiers in double-sided rows in a room equipped with a light/dark cycle (14 h of light). In floor pens, a total of 400 birds were randomly housed in 4 floor pens with 90 female and 10 male per pen $\left(2,800 \mathrm{~cm}^{2} /\right.$ bird $)$ under natural light conditions. The size of the floor pen was $400 \mathrm{~cm}$ in width by $700 \mathrm{~cm}$ in length by $380 \mathrm{~cm}$ in height with the slatted floor and sand ground. The floor pen consists of a laying nest area $(400 \mathrm{~cm} \times 300 \mathrm{~cm} \times 380 \mathrm{~cm})$ and a littered ground area $(400$ $\mathrm{cm} \times 400 \mathrm{~cm} \times 380 \mathrm{~cm}$ ). The floor pen was installed with four central bowel feeders, two bowel drinkers, perches and nests, which allowed the birds to permit free access to any part of the pen. The 3 levels of two perches measuring a total length of $220 \mathrm{~cm}$ were provided at one side of the pens. A laying nest measuring $50 \mathrm{~cm}$ by $120 \mathrm{~cm}$, with the floor slightly tilted from the rear to the front, was equipped at the back of pen.

\section{Body weight, organ weights and tissue sampling}

At the beginning and end of an experiment, forty hens 
representing the average body weight (BW) per housing system was used to monitor BW. Among them, eight hens weighing average BW per housing system were sacrificed to harvest tissue samples at the end of feeding trial. Immediately after euthanizing by cervical dislocation, firstly blood samples were taken by cutting the neck veins of hens and spilling blood into previously heparin coated sterile tubes. Next, several immune-related organs including the liver, spleen, thymus and the bursa of Fabricius were harvested and weighed immediately following dissection. The organs were gently soaked into $0.9 \%$ ice-cold saline to remove remaining blood. All harvested tissues were rapidly frozen in liquid nitrogen and stored at $-70^{\circ} \mathrm{C}$ until further assay.

\section{Assays for physiological and immunological parameters}

Whole blood was used for the isolation of plasma to analyze biochemical profiles, corticosterone and IgG. Blood biochemical components including glucose, total protein, albumin, cholesterol, triglyceride, alanine aminotransferase (ALT) and aspartate aminotransferase (AST) were assayed with the procedure and corresponding kit supplied by manufacturer using Automatic Biochemical Analyzer (IDEXXVET TEST, ME, USA). Corticosterone (CORT) was assayed by enzyme-immunoassay using a commercial kit(901-0907, Assay Designs Inc., Ann Arbor, MI. USA) according to the instructions provided with kit. Briefly, $100 \mu$ of standard solutions and appropriately diluted plasma were loaded into an individual test well. Fifty $\mu$ l of conjugate and antibody were pipetted into each well and incubated for $2 \mathrm{~h}$. After incubation, the contents of the wells were discarded and washed 3 times with washing solution. A solution of p-nitrophenyl phosphate was added to each well and incubated for $1 \mathrm{~h}$. Immediately after adding $50 \mu \mathrm{l}$ of stop solution, absorbance was determined using an ELISA reader $\left(\mathrm{V}_{\max }\right.$ Molecular Device, CA, USA) with its wavelength set at $405 \mathrm{~nm}$. Plasma IgG was assayed by the Chicken IgG plate kit (ECOS Institute, Miyagi, Japan). In brief, $5 \mu l$ of standard solutions (A and B) and appropriately diluted plasma were loaded into an individual test well of chicken IgG plate. After firmly securing the plate cover, the plate was placed in a humidified incubator at room temperature for 48 hours. After incubation, the external diameter of each precipitin ring was measured. Next, the IgG concentration of diluted plasma was calculated from the reference curve of

standard solutions.

To extract total RNA from the liver and spleen, the method of RNAsol ${ }^{\mathrm{TM}} \mathrm{B}$ (Tel-Test Inc, Friendswood, TX) was applied. Briefly, $100 \mathrm{mg}$ of tissue was removed from each organ and added to $1 \mathrm{ml}$ of RNAsol solution. The tissues were homogenized using glass-glass homogenizer. The lysate was transferred to microcentrifuge tube and added to $1 / 10$ vol. of chloroform to remove protein extract. The aqueous phase was separated by centrifugation for $15 \mathrm{~min}$ at 15,000 rpm. Total RNA was precipitated with the same vol. of isopropanol and centrifuged for $15 \mathrm{~min}$ at $15,000 \mathrm{rpm}$. The precipitated total RNA was washed with $75 \%$ ethyl alcohol, dried and diluted with diethylpyrocarbonate (DEPC) treated water. The concentration of isolated total mRNA was determined by spectrophotometer (GeneQuant pro, Amersham, USA) and confirmed on a $1.0 \%$ agarose gel stained with Ethidium bromide (EtBr).

Quantification of mRNA using reverse transcriptase PCR (RT-PCR) was performed to quantify mRNA of the cytokines such as interleukin-1 $\beta$ (IL-1 $\beta$ ), IL-6, IL-10, interferon-gamma (IFN- $\gamma$ ), lipopolysaccharide- induced tumor necrosis factor- $a$ factor (LITAF) and inducible nitric oxide synthase(iNOS). The cDNA primers used to amplify each gene are listed in Table 1. Briefly, for synthesis of the first strand cDNA, 1.0 $\mu \mathrm{g}$ of total RNA was incubated at $62^{\circ} \mathrm{C}$ for $10 \mathrm{~min}$ with 1.0 $\mu \mathrm{g}$ of oligo dT (Invitrogen Inc, Carlsbad, Ca). Next, the resulting solution was incubated at $42^{\circ} \mathrm{C}$ for $50 \mathrm{~min}$ in a reaction mixture containing $2.5 \mathrm{mM}$ dNTP and 200 units reverse transcriptase (Takara Inc, Shiga, Japan). After that, 3.2 units RNAase $\mathrm{H}$ was used to remove RNA hybridized with cDNA for $30 \mathrm{~min}$ at $37^{\circ} \mathrm{C}$. The amplification of obtained RNA was performed for 32 cycles of denaturation at $94^{\circ} \mathrm{C}$ for $30 \mathrm{sec}$, annealing at $62^{\circ} \mathrm{C}$ for $30 \mathrm{sec}$ and extension at $72^{\circ} \mathrm{C}$ for $10 \mathrm{~min}$. The reaction mixture consisted of 10 pmol primers, $2.5 \mu \mathrm{g}$ cDNA, $2.5 \mathrm{mM} \mathrm{dNTP}$ and 1 unit Taq polymerase (Takara Inc, Shiga, Japan). We determined the number of cycles and kept the products within the exponential phase. The density of each product in agarose gel electrophoresis (1.5\%) containing $\mathrm{EtBr}$ was measured using densitometer(Gel documentation system, EasyDoc, Korea). Levels of all mRNAs were expressed as the ratio of signal intensity for genes relative to that for $\beta$ actin.

\section{Statistical analysis}


Table 1. Primers used for quantification of RT-PCR

\begin{tabular}{|c|c|c|c|}
\hline Target Cytokines & Primer sequences & Product size (bp) & Gene bank Accession No. \\
\hline \multirow{2}{*}{ IL-1 $\beta$} & 5'-GCT CTA CAT GTC GTG TGT GA-3' & \multirow{2}{*}{167} & \multirow{2}{*}{ AJ245728 } \\
\hline & 5'-TGT CGA TGT CCC GCA TGA-3' & & \\
\hline \multirow{2}{*}{ IL-6 } & 5'-GCT CGG AAC AAC CTC AAC CT-3' & \multirow{2}{*}{247} & \multirow{2}{*}{ EU170468 } \\
\hline & 5'-CTG GGA TGA CCA CTT CAT CG-3' & & \\
\hline \multirow{2}{*}{ IL-10 } & 5'-GCA GAC CAG CAC CAG TCA TC-3' & \multirow{2}{*}{185} & \multirow{2}{*}{ XM425823 } \\
\hline & 5'-ACT CCC CCA TGG CTT TGT AG-3' & & \\
\hline \multirow{2}{*}{ IFN- $\gamma$} & 5'-TTC CTT CAT TTT CCT CTT GA-3' & \multirow{2}{*}{294} & \multirow{2}{*}{ Y07922 } \\
\hline & 5'-ACT GGA AAA CAC AAG GTC AC-3' & & \\
\hline \multirow{2}{*}{ LITAF } & 5'-GAA CTA TCC TCA CCC CTA CC-3' & \multirow{2}{*}{223} & \multirow{2}{*}{ AY765397 } \\
\hline & 5'-TGA CTC ATA GCA GAG ACG TG-3' & & \\
\hline \multirow{2}{*}{ iNOS } & 5'-GCA TCC AAA ATA TGA GTG GT-3' & \multirow{2}{*}{274} & \multirow{2}{*}{ U34045 } \\
\hline & 5'-AAG CAC AGC CAC ATT TAT CT-3' & & \\
\hline \multirow{2}{*}{$\beta$-actin } & 5'-GTG GGG CGC CCC AGG CAC CA-3' & \multirow{2}{*}{540} & \multirow{2}{*}{ NM001101 } \\
\hline & 5'-CTC CTT AAT GTC ACG CAC GA-3' & & \\
\hline
\end{tabular}

The effects of the two different housing conditions on BW, organ weights, blood biochemical values and cytokine expression were analyzed by Proc t-test (SAS Institute Inc., 1989). The level of probability for statistical difference was established at $\mathrm{P}<0.05$. Data are presented as means $\pm \mathrm{SE}$.

\section{RESULTS}

\section{BW and organ weights}

The effects of the two different housing conditions from puberty (16 weeks old) until the age of 40 weeks of laying hens on BW and organ weights are presented in Table 2. The hens housed in floor pens with lower stocking density had significantly $(\mathrm{P}<0.05)$ higher $\mathrm{BW}$ compared with those housed in conventional cages with higher stocking density. Final BW of the hens reared in floor pens and conventional cages resulted in $189 \%$ and $154 \%$ increases, respectively when compared with their initial BW aged 16 weeks. However, there was no statistical difference in relative immune-related organ weights including the liver, spleen, thymus and bursa of Fabricius between two groups, although absolute organ weights of the hens housed in floor pens tended to increase. Overall, the hens housed in conventional cages with higher stocking density resulted in a significantly $(\mathrm{P}<0.05)$ lower $\mathrm{BW}$ without affecting relative organ weights compared with those housed in floor pens with lower stocking density for 24 weeks period.
Table 2. Effects of different housing systems on body weight and organ weights in White Leghorn hens

\begin{tabular}{lcc}
\hline & \multicolumn{2}{c}{ Housing Systems } \\
\cline { 2 - 3 } & $\begin{array}{c}\text { Conventional } \\
\text { cage }\end{array}$ & Floor pen \\
\hline \hline Initial BW, g & $929.8 \pm 8.49$ & $930.1 \pm 7.17$ \\
Final BW, g & $1,433.9 \pm 31.14$ & $1,757.5 \pm 14.33^{*}$ \\
Liver, g & $41.73 \pm 2.58$ & $46.89 \pm 2.52$ \\
Liver, g/100g BW & $2.91 \pm 0.14$ & $2.67 \pm 0.11$ \\
Spleen, g & $1.43 \pm 0.10$ & $1.60 \pm 0.06$ \\
Spleen, g/100g BW & $0.10 \pm 0.009$ & $0.09 \pm 0.004$ \\
Thymus, g & $0.395 \pm 0.046$ & $0.328 \pm 0.041$ \\
Thymus, g/100g BW & $0.028 \pm 0.003$ & $0.023 \pm 0.004$ \\
Bursa of Fabricius, g & $0.31 \pm 0.05$ & $0.39 \pm 0.07$ \\
Bursa of Fabricius, & $0.022 \pm 0.004$ & $0.030 \pm 0.008$ \\
$\quad$ g/100g BW & &
\end{tabular}

Values of BW are means per housing system $(n=40)$ with SE.

Values of organ weight are means per housing system $(n=8)$ with SE. The treatment groups contained $810 \mathrm{~cm}^{2} /$ bird and $2,800 \mathrm{~cm}^{2} /$ bird in conventional ages and floor pens, respectively.

Asterisk $(*)$ indicates significant difference between the two housing systems at $\mathrm{P}<0.05$.

\section{Plasma biochemical profiles, CORT and IgG}

Changes in plasma biochemical profiles and the levels of $\operatorname{IgG}$ and CORT in the hens housed in different housing conditions are shown in Table 3 and Fig. 1, respectively. Glucose, triglyceride, total protein and AST were not 
Table 3. Effects of different housing systems on plasma biochemical profiles in White Leghorn hens

\begin{tabular}{lcc}
\hline & \multicolumn{3}{c}{ Housing Systems } \\
\cline { 2 - 3 } & Conventional cage & Floor pen \\
\hline \hline Glucose, $\mathrm{mg} / \mathrm{d} \ell$ & $281.4 \pm 6.67$ & $262.3 \pm 10.62$ \\
Triglyceride, $\mathrm{mg} / \mathrm{d} \ell$ & $1,327.8 \pm 274.5$ & $1,257.6 \pm 289.0$ \\
Cholesterol, $\mathrm{mg} / \mathrm{d} \ell$ & $132.9 \pm 18.9^{*}$ & $78.3 \pm 9.42$ \\
Total protein, g/d $\ell$ & $5.46 \pm 0.08$ & $5.48 \pm 0.12$ \\
ALT, U/ $\ell$ & $31.88 \pm 3.10^{*}$ & $21.00 \pm 1.86$ \\
AST, $\mathrm{U} / \ell$ & $10.63 \pm 0.15$ & $11.10 \pm 0.19$ \\
\hline
\end{tabular}

Values are means per housing system $(\mathrm{n}=8)$ with SE.

The treatment groups contained $810 \mathrm{~cm}^{2} /$ bird and $2,800 \mathrm{~cm}^{2} /$ bird in conventional ages and floor pens, respectively.

ALT and AST indicated Alanine aminotransferase and aspartate aminotransferase, respectively.

Asterisk $(*)$ indicates significant difference between the two housing systems at $\mathrm{P}<0.05$.

affected by different housing conditions. However, plasma cholesterol and ALT levels were significantly $(\mathrm{P}<0.05)$ lowered in the hens housed in floor pens compared with

(A)

$\square$ Conventional cage $\quad$ Floor pen

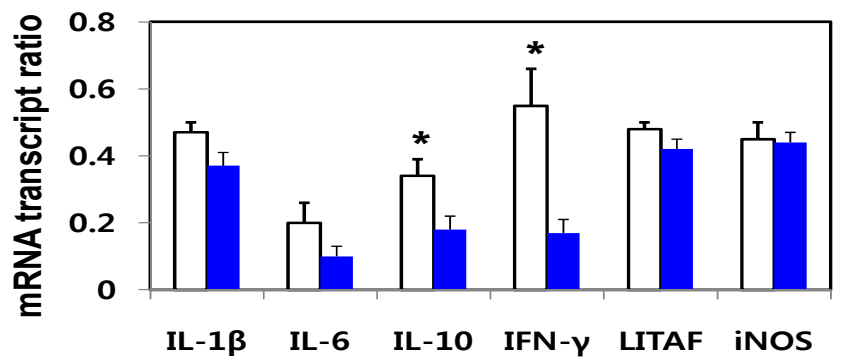

(C)

$\square$ Conventional cage $\quad$ Floor pen

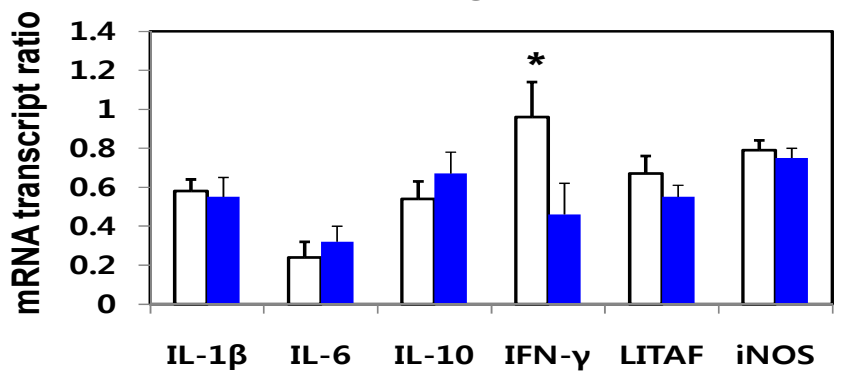

$\square_{\mathrm{IgG}} \square$ Corticosterone

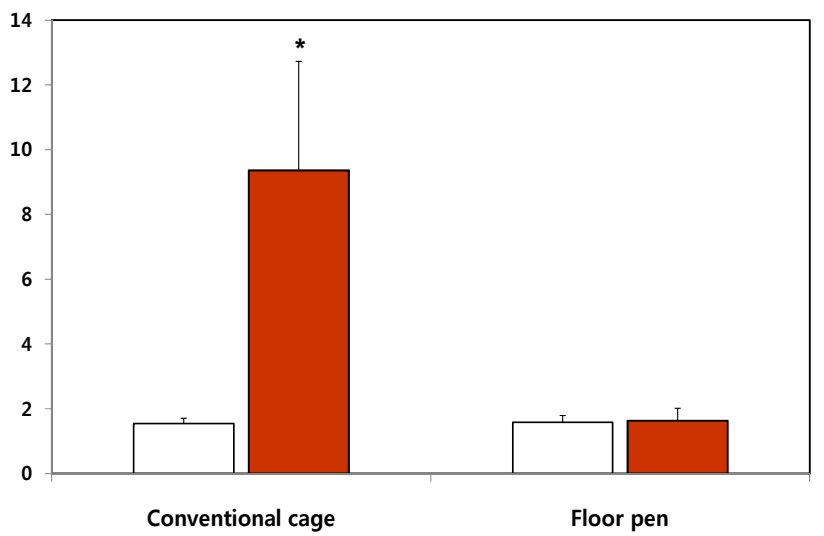

Fig. 1. The levels of plasma $\operatorname{lgG}(\mathrm{mg} / \mathrm{m} \ell, \square)$ and corticosterone $(\mathrm{ng} / \mathrm{m} \ell, \boldsymbol{\square})$ of White Leghorn hens housed in conventional cages $\left(810 \mathrm{~cm}^{2} /\right.$ bird) and floor pens $\left(2,800 \mathrm{~cm}^{2} /\right.$ bird $)$. Values are means per housing system $(n=8)$ with SE shown by vertical bars. Asterisk $(*)$ indicates significant difference between two housing systems at $\mathrm{P}<0.05$.

(B)

\section{$\square$ Conventional cage $\quad$ Floor pen}

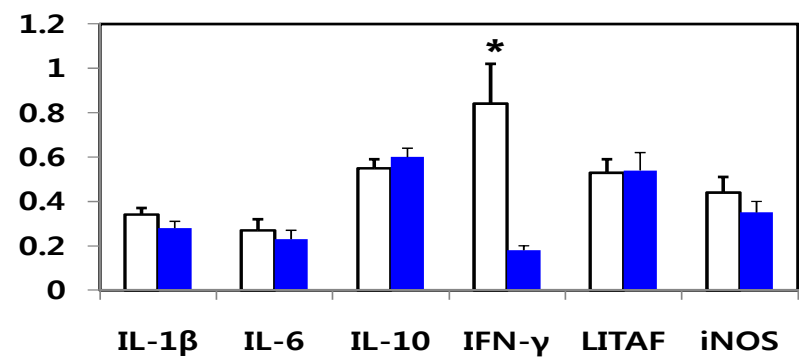

(D) $\square$ Conventional cage $\square$ Floor pen

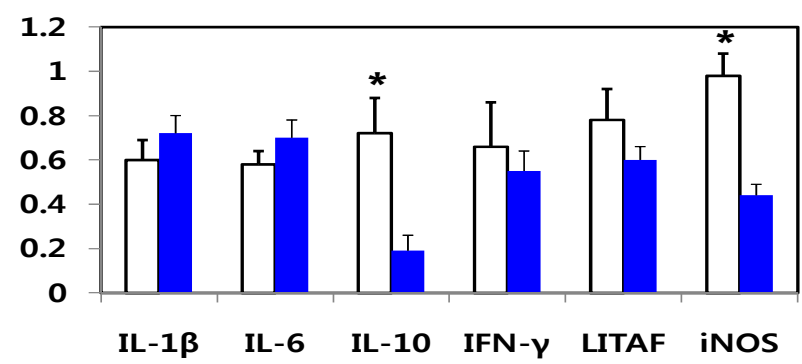

Fig. 2. Semi-quantification of mRNA expressions of IL-1 $\beta, I L-6, I L-10, I F N-\gamma$, LITAF and iNOS of the liver (A), spleen (B), thymus $(C)$ and bursa of Fabricius (D) in White Leghorn hens housed in conventional cages ( $\square, 810 \mathrm{~cm}^{2} /$ bird $)$ and floor pens $\left(\boldsymbol{\square}, 2,800 \mathrm{~cm}^{2} /\right.$ bird). Levels of all mRNA transcript ratios were expressed as the value of signal intensity for genes relative to that for $\beta$-actin. Values are means per housing system $(n=8)$ with SE shown by vertical bars. Asterisk $(*)$ indicates significant difference between housing systems at $P<0.05$. 
those in conventional cages (Table 3). Compared with the hens housed in floor pens, plasma CORT level was significantly higher $(\mathrm{P}<0.05)$ in the hens kept in conventional cages as depicted in Fig. 1. In addition, IgG level seemed to be not affected by the housing systems after 24 weeks of housing period in White Leghorn hens (Fig. 1).

\section{Expression of pro-inflammatory cytokines in the immune organs}

The mRNA expression levels of IL-1 $\beta$, IL-6, IL-10, IFN$\gamma$, LITAF and iNOS in non-lymphoid (liver) and lymphoid (spleen, thymus and the bursa of Fabricius) organs of the hens housed in two different conditions are shown in Figure 2. The hepatic expression levels of IL-10 and IFN- $\gamma$ were significantly $(\mathrm{P}<0.05)$ higher in the hens housed in conventional cages than those kept in floor pens (Fig. 2A). However, no significant difference in the expression levels of hepatic IL-6, LITAF and iNOS was observed between the two housing conditions. In the spleen, which is a secondary lymphoid organ that stimulates the immune response against acquired antigens, housing floor pens significantly $(\mathrm{P}<0.05)$ up-regulated the expressional level of IFN- $\gamma$, whereas the other cytokines were not affected by housing conditions in hens (Fig. 2B). In the thymus, a primary lymphoid organ, the expression level of IFN- $\gamma$ but not the other cytokines was remarkably $(\mathrm{P}<0.05)$ enhanced in the hens housed in conventional cages compared with those in floor pens (Fig. 2C). In regard to the cytokine expression of the Bursa of Fabricius, housing in conventional cages significantly $(\mathrm{P}<$ 0.05 ) increased the expression of pro-inflammatory cytokines including IL-10 and iNOS compared with housing in floor pens (Fig. 2D).

\section{DISCUSSION}

Social stressors caused by housing conditions including multiple tier cages with overcrowding resulted in laying hens with more susceptibility to pathogens and the occurrence of abnormal behaviors, leading to the treat of bird health and welfare (Awadalla, 1998; Freire et al., 2003; Zimmerman et al., 2006). In the present study, we applied two different housing conditions (conventional cages with higher stocking density vs. floor pens with lower stocking density) to investigate the combined effects of two chronic social stressors on physiological and immunological responses. As expected, the hens housed in conventional cages with higher stocking density for 24 weeks resulted in a significantly lower BW, showing that housing conditions induced severe social stressors in laying hens. A similar result conducted by Pohle and Cheng (2009) reported that the hens kept in conventional cages were significantly lower in BW compared with those kept in furnished cages.

We continuously examined plasma biochemical parameters including cholesterol and CORT to clarify whether social stressors caused by housing conditions could affect these parameters in hens. In the present data, the hens housed in floor pens with lower stocking density showed lower plasma cholesterol and CORT levels than those housed in conventional cages with higher stocking density. Hypercholesterolemia is an indicator of hyperactivity of the adrenal gland (Siegal, 1995). A significantly lower serum cholesterol level was observed in the heat stressed birds compared with the control group (Sohail et al., 2010). Furthermore, CORT, widely recognized as a criterion of stress response, has been shown to increase when the birds were exposed to various stressors such as transportation, heat, feed and water deprivation and severe competition via the stimulation of hypothalamic-pituitary-adrenal axis (Tempel and Leibowitz, 1994; Cheng and Muir, 2004; Rettenbache and Palme, 2009). Pohle and Cheng(2009) demonstrated that CORT level increased in the hens housed in the conventional cages, but not in those housed in the furnished cages, suggesting that social stressor induced by housing conditions have a significant impact on the stress responses. Gibson et al. (1986) reported that plasma CORT level was lower in the hens from straw yards than in those from cages and range, albeit plasma CORT was not effective indicator of long-term stress or welfare. In laying hens, there also seems to exist a positive correlation between social fear and CORT levels in birds. Cheng and Muir(2004) reported that laying hens showed a significantly lower plasma CORT level in single bird cages $\left(525 \mathrm{~cm}^{2} /\right.$ bird $)$ than in the 10-bird cages $\left(419 \mathrm{~cm}^{2} /\right.$ bird), indicating that social stressor could be a factor to produce high CORT in hens. This result is somewhat in agreement with our observation that CORT level was lower in the hens housed in floor pens with much lower stocking density, because they had enough space and facilities to avoid from fear and attack. It is now evident that CORT has multifunctional roles in the regulation of behavior, endocrine and immunity for coping strategy against stressors (Haller et al., 2000; Fahey and Cheng, 2008). On the other 
hand, several studies reported that social stressors or stocking density alone had no significant effect on plasma CORT level (Cheng and Muir, 2004; Nicol et al., 2006), although various instances of abnormal behavior of birds have been related to social stress or stocking density (Zimmerman et al., 2006; Platz et al., 2009).

Furthermore, it is necessary to investigate humoral and cellular immune parameters that can be applied to assess the effect of different housing conditions on immune responses as stress indicators because increased CORT production attributed to a variety of stressors may cause the adaptive responses of immune functions (Felten et al., 1998; Shini et al., 2010b). The most important effects of stressors on the adaptive immunity are associated with two different cell types; B-lymphocytes (IgG production for humoral immunity) and T-lymphocytes (CD4 and CD8 which are associated with inflammatory cytokines for cellular immunity) (Janeway et al. 2001). In the present data, we did not see difference in IgG level between the two housing conditions, although plasma CORT level increased in the hens housed in conventional cages. Our results are consistent with those of the previous study in that different housing systems (furnished cages vs. battery cages) did not affect the circulating IgG level in hens (Pohle and Cheng, 2009). It could be thought that much more severe and prolonged stressors or the exposure of a variety of antigens might affect the modulation of apparent humoral immune responses in laying hens.

In particular, there is as of yet little known about the effects of housing conditions on the cellular immune indicators such as pro-inflammatory cytokines in birds. The pro-inflammatory cytokines, IL-1 $\beta$, IL-6, IL-10, IFN- $\gamma$ and LITAF, which are widely expressed in lymphoid and nonlymphoid tissues of birds, are the most powerful cognitive pathways in response to inflammatory process (Hong et al., 2006; Kaiser et al., 2009). Moreover, iNOS is another important gene that might be associated with the inflammatory process, since nitric oxide formed by iNOS has emerged as a multifunctional molecule that plays an important role in the regulation of pro-inflammatory cytokines (Guzik et al., 2003). In the present data, hepatic IL-10 and IFN- $\gamma$, proinflammatory cytokines, were elevated in the hens housed in conventional cages compared with those kept in floor pens. Moreover, IFN- $\gamma$ expression in the spleen and thymus was also higher in the hens kept in conventional cages. The expression of IL-10 and iNOS in the bursa of Fabricius was also up-regulated in the hens housed in conventional cages.
Based upon our observations, particularly up-regulated IFN$\gamma$ and IL-10 might be effective cytokines to assess housing stressor of hens under our circumstances. IFN- $\gamma$, a powerful cytokine which is involved in differentiation of cytotoxic T-cells, has an important role in the amplification of immune response against certain inductors including bacterial species (Sadeyen et al., 2004). IL-10, mainly produced by activated macrophages in the bursa of Fabricius, is also involved in cell-mediated immune functions (Groux and Powrie, 1999). Thus, it might be speculated that social stressors caused by housing conditions activated the expression of certain proinflammatory cytokines in immune organs possibly through increased adrenal activity via CORT production. In agreement with our study, several studies reported that the expressions of pro-inflammatory cytokines including IL-1 $\beta$, IL-6 and IL-10 mRNA of blood and splenic lymphocytes in laying hens were markedly enhanced during CORT-induced stress, suggesting that increased CORT might modulate the immune function by activating pro-inflammatory cytokines (Shini and Kaiser, 2009; Shini et al., 2010b). Cold stress in birds has been reported to increase pro-inflammatory cytokines such as IL-1 $\beta$, IL-6 and IL-12 (Hangalapura et al., 2006) and iNOS in intestinal tissue (Zhang et al., 2011). A recent study conducted by our group reported that the combined stressor induced by stocking density and feed restriction significantly increased the expression of pro-inflammatory cytokines including IL-6 and iNOS in hens (Kang et al., 2011). In contrast, a significant decreased expression of pro-inflammatory cytokines by chronic treatment of CORT from the birds suggested that chronic and severe stress could suppress the immunity (Shini and Kaiser, 2009). It also seemed that each pro-inflammatory cytokine against stressors responded differently, depending upon the sort of stressors, nutritional status, genetic background, etc. (Hangalapura, et al., 2006; Kang et al., 2011). Even, it was reported that proinflammatory cytokine expression in peripheral blood was different from that in the spleen in response to stressors (Shini and Kaiser, 2009). Therefore, the underlying mechanism of pro-inflammatory cytokine responses caused by stressors is inherently complex in the fact that cytokine expression is affected by all external and internal living conditions as well as interacting stressors. According to various approaches, thus, it is postulated that either up- or down-regulation of certain pro-inflammatory cytokine expression is associated with integrated stress-induced responses in birds to cope with environmental stressors to maintain homeostasis through 
immune mechanism (Shini et al., 2010a).

In summary, housing hens in conventional cages with higher density markedly affected BW, cholesterol, CORT production and some pro-inflammatory cytokine expression in immune organs, leading to potential social stress-related responses in laying hens. Thus, it can be drawn that an increased cholesterol and CORT levels in the hens exposed to chronic social stressors may be associated with activated expression of pro-inflammatory cytokines under these circumstances. More detailed studies under various circumstances are still needed to explore the ways of assessing stress and welfare in birds.

\section{ACKNOWLEDGEMENT}

This research was supported by a grant from NextGeneration Biogreen 21 (No. PJ007981), Rural Development Administration, Ministry for Food, Agriculture, Forestry and Fisheries, Republic of Korea

\section{REFERENCES}

Albentosa, M. J. and Cooper, J. J. 2004. Effects of cage light and stocking on the frequency of comfort behaviors performed by laying hens in furnished cages. Anim. Welfare 13:419-424.

Awadalla, S. F. 1998. Effect of some stressors on pathogenicity of Eimeria tenella in broiler chicken. J. Egypt. Soc. Parasitol. 28: 683-690.

Baxter, M. R. 1994. The welfare problems of laying hens in battery cages. Vet. Rec. 134:614-619.

Buijs, S., Keeling, L., Rettenbacher, S., Van Poucke, E. and Tuyttens, F. A. 2009. Stocking density effects on broiler welfare: identifying sensitive ranges for different indicators. Poult. Sci. 88(8):1536-1543.

Cheng, H. W. and Muri, W. M. 2004. Chronic social stress differentially regulates neuroendocrine response in laying hens: II. Genetic basis of adrenal responses under three different social conditions. Psychoneurodenocrinlogy 29:961-971.

Cook, M. E. 1991. Nutrition and immune response of the domestic fowl. CRC Crit. Rev. Poult. Biol. 3:167-189.

Fahey, A. G. and Cheng, H. W. 2008. Effects of social disruption on physical parameter corticosterone concentrations, and immune system in two genetic lines of White Leghorn layers. Poult. Sci. 87(10):1947-1954.

Felten, S. Y., Madden, K. S., Bellinger, D. L., Kruszewska, B., Moynihan, J. A. and Felten, D. L. 1998. The role of the sympathetic nervous system in the modulation of immune responses. Adv. Pharmacol. 42:583-587.

Freire, R., Wilkins, L. J., Short, F. and Nicol, C. J. 2003. Behaviour and welfare of individual laying hens in a non-cage system. Br. Poult. Sci. 44:22-29.

Gibson, S. W., Hughes, B. D., Harvey, S. and Dun, P. 1986. Plasma concentrations of corticosterone and thyroid hormones in laying fowls from different housing system. Br. Poult. Sci. 27(4):621-628.

Groux, H. and Powrie, F. 1999. Regulatory T cells and inflammatory bowel disease. Immunol. Today. 20:442-445.

Guzik, T. J., Korbut, R. and Adamek-Guzik, T. 2003. Nitric oxide and superoxide in inflammation and immune regulation. J. Physiol. Pharmacol. 54(4):469-487.

Haller, J., Millar, S., van de Schraaf, J., de Kloet, R. E. and Kruk, M. R. 2000. The active phase-related increase in corticosterone and aggression are linked. J. Neuroendocrinol. 12(5):431-436.

Hangalapura, B. N., Kaiser, M. G., Poel, J. J., Parmentier, H. K. and Lamont, S. J. 2006. Cold stress equally enhances in vivo pro-inflammatory cytokine gene expression in chicken lines divergently selected for antibody responses. Dev. Comp. Immunol. 30(5):503-511.

Hong, Y. H., Lillehoj, H. S., Lee, S. H., Park, D. W. and Lillehoj, E. P. 2006. Molecular cloning and characterization of chicken lipopolysaccharide-induced TNF-alpha factor(LITAF). Dev. Comp. Immunol. 30(10):919-929.

Janeway, C. A., Travers, P., Walport, M. and Shlomchik, M. 2001. The adaptive immune responses. Pages 295-381 in Immunology V. ed. C. A. Janeway. Garland Publishing New York, NY.

Kaiser, P., Wu, Z., Rothwell, L., Fife, M., Gibson, M., Poh, T. Y., Shini, A., Bryden, A. W. and Shini, A. 2009. Prospects for understanding immune-endocrine interactions in the chicken. Gen. Comp. Endocrinol. 163(1-2):83-91.

Kang, S. Y., Ko, T. H., Moon, Y. S., Sohn, S. H. and Jang, I. S. 2011. Effect of combined stress induced by stocking density and feed restriction on hematological and cytokine parameters as stress indicators in laying hens. Asian-Aust. J. Anim. Sci. 24(3):414-420.

Mashaly, M. M., Hendricks 3rd, G. L., Kalama, M. A., Gehad, A. E., Abbas, A. O. and Patterson, P. H. 2004. Effect of heat stress on production parameters and immune responses of commercial laying hens. Poult. Sci. 83(6):889-894.

Mashaly, M. M., Webb, M. L., Youtz, S. L., Roush, W. B. and Graves, H. B. 1984. Changes in serum corticosterone concentration of laying hens as a response to increased 
population density. Poult.Sci. 63(11):2271-2274.

Nicol, C. J., Brown, S. N., Glen, E., Pope, S. J., Short, F. J., Warriss, P. D., Zimmerman, P. H. and Wilkins, L. J. 2006. Effects of stocking density, flock size and management on the welfare of laying hens in single-tier aviaries. Br. Poult. Sci. 47(2):135-146.

Nicol, C. J. 1987. Behavioural responses of laying hens following aperiod of spatial restriction. Anim. Behav. 35:522-527.

Platz, S., Heyn, E., Hergt, F., Weigl, B. and Erhard, M. 2009. Comparative study on the behaviour, health and productivity of laying hens in a furnished cage and an aviary system. Berl. Munch. Tierarztl. Wochenschr. 122(7-8):235-240.

Pohle, K. and Cheng, H. W. 2009. Comparative effects of furnished and battery cages on egg production and physiological parameters in White Leghorn hens. Poult. Sci. 88:2042-2051.

Puvadolpirod, S. and Thaxton, J. P. 2000. Model of physiological stress in chickens 1. Response parameters. Poult. Sci. 79(3): 363-369.

Rettenbacher, S. and Palme, R. 2009. Biological validation of a non-invasive method for stress assessment in chickens. Berl. Munch. Tierarztl. Wochenschr. 122:8-12.

Rodenburg, T. B., Tuyttens, F. A., Sonck, B., De Reu, K., Herman, L. and Zoons, J. 2005. Welfare, health, and hygiene of laying hens housed in furnished cages and in alternative housing systems. J. Appl. Anim. Welf. Sci. 8(3):211-26.

Sadeyen, J. R., Trotereau, J., Protais, J., Beaumont, C., Sellier, N., Salvat, G., Velge, P. and Lalmanach, A. C. 2006. Salmonella carrier-state in hens: study of host resistance by a gene expression approach. Microbes Infect. 8(5):1308-1314.

SAS. 1989. SAS / STAT User's Guide, Version $6,4^{\text {th }}$ Edition. Vol 2. SAS Ins., Cary, NC.

Sherwin, C. M., Richards, G. J. and Nicol, C. 2010. Comparison of the welfare of layer hens in 4 housing systems in the UK. Br. Poult. Sci. 51(4):488-499.

Shini, S. 2003. Physiological responses of laying hens to the alternative housing system. Int. J. Poult. Sci. 2:357-360.

Shini, S., Huff, G. R., Shini, A. and Kaiser, P. 2010a. Under- standing stress-induced immunosuppression: Exploration of cytokine and chemokine gene profiles in chicken peripheral leukocytes. Poult. Sci. 89:841-851.

Shini, S., Shini, A. and Kaiser, P. 2010b. Cytokine and chemokine gene expression profiles in heterophiles from chickens treated with corticosterone. Stress. 13(3):185-194.

Shini, S. and Kaiser, P. 2009. Effects of stress, mimicked by administration of corticosterone in drinking water, on the expression of chicken cytokine and chemokine genes in lymphocytes. Stress 12(5):388-399.

Siegal, H. S. 1985. Immunological responses as indicators of stress. World's Poult. Sci. J. 41:36-44.

Siegal, H. S. 1995. Stress, strains and resistance. Br. Poult. Sci. 36:3-22.

Singh, R., Cook, N., Cheng, K. M. and Silversides, F. G. 2009. Invasive and noninvasive measurement of stress in laying hens kept in conventional cages and in floor pens. Poult. Sci. 88(7):1346-1351.

Sohail, M. U., Ijaz, A., Yousaf, M. S., Ashraf, K., Zaneb, H., Aleem, M. A. and Rehman, H. 2010. Alleviation of cyclic heat stress in broilers by dietary supplementation of mannanoligosaccharide and Lactobacillus-based probiotic: Dynamics of cortisol, thyroid hormone, cholesterol, C-reactive protein, and humoral immunity. Poult. Sci. 89:1934-1938.

Tempel, D. L. and Leibowitz, S. F. 1994. Adrenal steroid receptors: interactions with brain neuropeptide systems in relation to nutrient intake and metabolism. J. Neuroendocrinol. 6(5):479-501.

Zhang, Z. W., Lv, Z. H., Li, J. L., Li, S., Xu, S. W. and Wang, X. L. 2011. Effects of cold stress on nitric oxide in duodenum of chicks. Poult. Sci. 90(7):1555-1561.

Zimmerman, P. H., Lindberg, A. C., Pope, S. J., Glen, E., Bolhuis, J. E. and Nicol, C. J. 2006. The effect of stocking density, flock size and modified management on laying hen behavior and welfare in a non-cage system. Appl. Anim. Behav. Sci. 101:111-124.

(Received Feb. 7, 2013; Revised Apr. 23, 2013; Accepted Apr. 24, 2013) 